\title{
Interactions on Facebook and Twitter: A Communicative Action Perspective
}

\author{
Sopuruchi Christian Aboh \\ Department of Linguistics, Igbo and Other Nigerian Languages, University of Nigeria, Nsukka, Nigeria \\ Obiageli Chika Ezeudo \\ Department of Linguistics, Nnamdi Azikiwe University, Awka, Nigeria
}

\begin{abstract}
The study examines interactions on Facebook and Twitter from a communicative action perspective. The objectives of this study are to: identify the nature of action(s) by interlocutors on Facebook and Twitter and examine the world(s) portrayed by these interlocutors. The study adopts Habermas' theory of communicative action to study the nature of actions and the three-world concept that exist among users of Facebook and Twitter. Insights from interpersonal pragmatics and politeness were also found useful in the analysis of data. A total number of 275 messages were used comprising five posts from Facebook with randomly selected 165 comments and three tweets with randomly selected 102 comments. The research observes that most participants on Facebook and Twitter acted or commented strategically in the sense that the stance they took were motivated by reasons and facts and not merely opinions or emotions. The findings also reveal that many interactants showed that they operate in the objective world by abiding by the social norms and facts.
\end{abstract}

Index Terms — communicative action, three-world concept, pragmatics, social networking sites, Habermas

\section{INTRODUCTION}

Interpersonal interactions have moved from face-to-face interaction to computer-mediated or electronically-mediated discourse. Social networking sites (SNSs), through the internet, have fostered communication amongst people from different parts of the world. Information, in the present dispensation, can be disseminated in nanoseconds. People from different parts of the world have been able to interact with people through social media like Facebook, Twitter, Instagram, WhatsApp, etc. Social network sites, contend Boyd and Ellison (2007), allow interactants to create a public or quasi-public profile within a bounded system and interact with a list of other users with whom they are in connection with. Admittedly, Varis and Bloomaert (2014) note that SNS performs the function of maintaining easy communication access among people.

Social media interactions have attracted the interest of researches. Within the linguistic parlance, these areas have been explored: ethnography and conversation analysis (West, 2015), communication style (Alvidrez \& Rodriguez, 2016), language variation and change (Ibe-Kalu, 2016; Bailey, 2018), code-switching (Habtoor \& Almutlagah, 2018; Alaslaa, 2018). As people interact on social media, they reveal their ideologies through the messages they send and the posts they share, retweet and/or forward. More so, personal relationships influence members' online interactional decisions and time of responses (West, 2015). This implies that people often reply the messages of those they are close to than the messages of people they are not closely related to. From the researches carried on interactions on social media, it could be seen that there is need to study interactions on Facebook and Twitter from a communicative action perspective, which is the justification for this study.

Facebook, Twitter and other social networking sites in the sociolinguistic parlance can be referred to as a speech community because there exist therein specific forms of language use that are only used in these sites and unacceptable in a formal setting. English has become the lingua franca of social media (Kim, Wei, Weber, Oh, 2014), although the world is not a 'global village' because the internet does not use a single language (Crystal, 2006). Inasmuch as there is no single language used on social media, English continues to be the most used language and participants use it to communicate and interact with one another.

The introduction of SNS has made it relatively difficult for one to have a private life. Two individuals who are friends on Facebook, for example, might attend a function together; one may not want to disclose to the cyber world that he was present at the function. The other person might make a post of a picture he took with the other person, tags him and uploads. In scenarios like this, Marvick and Boyd (2014) contend that privacy is discussed in terms of 'network privacy' and that information is interrelated and that people share information that implicates others. 'Network privacy' here refers to "trying to be in public without always being public" (Marwick \& Boyd, 2014, p. 2; emphasis in the original). This implies that an individual might be in his room alone but with his mobile device, he is communicating with many people. Suffice it to note that individuals often interact through computer-mediated platforms than face-to- 
face. This explains the reason a group of five persons will prefer interacting with people far from them than engaging in a face-to-face conversation with the people around them.

SNS has bridged the barriers of communication. As individuals interact on the social media, they exchange messages, reveal their ideologies and current activity, market their products or disseminate information. Since individuals on social media make use of language in their day-to-day discourses on social and since they are members of their individual societies or communities, studying the language use of interactants on social media becomes a task for sociolinguists. Sociolinguistics is generally defined as the relationship that exists between language and society (Wardhaugh 2010; Agbedo, 2015). Variationists examine the language variation and change manifesting in the posts and/or tweets of interactants. Speech act analysts will preoccupy themselves with Facebook Acts, Instagram Acts, and Twitter Acts. Conversational analysts examine the turn-taking patterns, adjacency pairs, and the procedures of initiating and ending interactions. Ethnographers using the ethnography of communication model seek to reveal the norms of interactions and the principles that guide any communicative event on social media. As such, the social media has provided another area of research for linguists. Crystal (2006) notes that researchers in the field of computer/electronically-mediated discourse analysis must be well-informed with the changes that occur on social media if they want their researches to be current and relevant.

As such, the present study analyses interactions in Facebook and Twitter from Habermas' communicative action perspective. A study from this perspective becomes imperative because in the post-truth era, a time when alternative facts spring up every day, people's post on social media need to be verified in order to discern if they align with the 'social world' or deviate from it. More so, individuals do not often verify information, which they share on social media, which does not concur with the truthfulness aspect of Habermas' theory of communicative action. In this study, posts and tweets obtained from Facebook and Twitter respectively and the comments on these posts and tweets will be analysed.

As observed by West (2015, p. 7), Facebook, which was begun in February of 2004 was originally set up as "an online facebook - a directory that includes photos and basic information about members of a community - specifically for Harvard students ("thefacebook.com")." As time proceeded, continues West (2015), members of the Facebook community increased. Different modifications have been made to Facebook ranging from having only the 'Like' option to the inclusion of other options like 'sad' 'love' etc. Facebook makes provision for group membership where people with the same interest can come and share ideas together.

On the other hand, Twitter as one of the social media platforms is where users post short messages of 280 characters (Bailey, 2018; Habtoor \& Almutlagah, 2018). According to Alvidrez and Rodriguez (2016, p. 2):

Twitter's speed and reach have made it a communication tool used widely by public figures to attract the attention of users, creating emotional bonds with their followers and, ultimately, mobilizing people to undertake a concrete action (for example: attending a film premiere, making donations for charitable causes, voting on election day).

In corroborating the above assertion, Alaslaa (2018) claims that Twitter is not the only social media service, but it stands out because of its message size, which has balanced and comparable corpora. He further remarks that Twitter provides a platform for the collection of data for most researches because millions of tweets are published on daily basis from individuals, groups and government agencies. Another feature that distinguishes Twitter from other social media platform, notes Alaslaa (2018), is that most of Twitter's data and tweets are available to the public, even to those who do not have Twitter accounts.

The above explications make Facebook and Twitter potent sources of data collection for a sociolinguistic research. The general objective of this study is to undertake an analysis of interactions in Facebook and Twitter from Habermas' theory of communicative action perspective. In specifics, the research seeks to: identify the nature of action(s) in Facebook and Twitter interactions and examine the world(s) portrayed by interlocutors on Facebook and Twitter;

This study is limited to selected posts on Facebook and the comments therein, and selected tweets and their comments on Twitter. Political discourse topics were obtained from Twitter whereas educational and relationship topics were obtained from Facebook.

\section{THEORETICAL FRAMEWORK}

The theory that serves as the theoretical framework of this research is Habermas' theory of communication action. The theory of communicative action was put forward by Jurgen Habermas, a German, in his two-volume publications in 1984 and 1987. The theory of communicative action gears towards investigating the way individuals communicate in accordance with the opinion of others, on the one hand; and takes decisions alone without considering the consequences on the society on the other hand. In essence, the theory of communication demands people to say the truth in order not to create a 'modal confusion.' Habermas (1984) argues that an action is considered communicative when participants in a discourse communicate in line with the 'objective,' 'social,' and 'subjective' worlds. By so doing, they get to know one another through deliberations, argument, cooperation and by sharing their subjective experiences, desires and feelings. Habermas (1987, p. 401) contends that under communicative action, individuals pursue different goals by engaging in different coordinated actions. 
Furthermore, Habermas (1984) opines that most people may not always do things that aim toward a common goal but an individual goal; this he refers to as 'instrumental action.' Instrumental action talks about nonsocial situation, which is self-centered. In this sense, instrumental actors accomplish their set objectives by manipulating other social actors as well as material objects. This then implies that individuals who engage in post-truth uses it to manipulate people in order to make their opinions to be adjudged as fact. In contrast to instrumental action is 'strategic action.' In this kind of action, Habermas (1984) purports that strategic actors, instead of manipulating others, pursue their objectives by convincing other actors because of the level of respect they have for them. This implies that social actors make use of deliberation and logical reasoning in pursuit of their goals.

Habermas' theory of communicative action recognises a three-world concept: 'objective,' 'social,' and 'subjective.' The objective world consists of 'the totality of what is the case' about entities and states of affairs, which agree or disagree with what is the case in the world. An actor can conceive something, which is not totally the case and may be right or wrong. Decision upon the outcome of his thoughts will be taken from the point of truth.

For the social world, Habermas (1984, p. 88) opines that it comprises a "normative context that lays down which interactions belong to legitimate interpersonal relations." In effect, the social world is the sum total of the values, traditions, and principles of a society. Notwithstanding, actors can concur or digress from these norms. When this happens, they will be judged based on the logical defense they are able to give. In essence, decisions are communally approved.

The 'subjective world,' notes Habermas (1984, p. 100), is "the totality of subjective experiences to which the actor has privileged access." In this world, the opinions and ideologies of an actor is made known to others.

In reacting to the theory of communicative action, Cecez-Kecmanovic and Janson (1999, p. 186) observe:

Communicative action exemplifies the concept of communicative rationality inherent in human speech, which denotes a communicative practice characterized by actors' obligation to give reasons for or against validity claims raised, to challenge, accept or reject claims of others on the bases of the better argument.

From the above excerpt, it becomes glaring that Habermas' theory of communication is against individuals swallowing ideas or information hook, line and sinker. He advocates the application of sound argument and logical/practical reasoning in checking any idea or pieces of information. This will aid in confirming the veracity of the idea, opinion, or information.

Essentially, another aspect of communicative action theory as enunciated by Habermas is that anyone acting communicatively must raise validity claims and suppose that they can be vindicated. As such, the speaker claims to be uttering something comprehensible, offering a true proposition, expressing his intentions truthfully so that the hearer can trust the speaker, and choosing an utterance that is right so that the hearer can accept the utterance with respect to a recognised normative background. It is only when these validity claims are justified in terms of 'comprensibility,' 'truth,' 'truthfulness,' and 'rightness' that communicative action can only occur correctly. Discerning an utterance that did not flout the validity claims can be done through 'rational reconstruction,' which implies using sentences and utterances to determine fundamental principles for understanding any practical use of language.

The theoretical framework used in this study is Habermas' theory of communicative action. The theory of communicative action takes precedence of objectivity over subjectivity. In using this theory in analysing data, two aspects of the theory will be employed: nature of action (instrumental or strategic), and the three-world concept (objective, social, subjective). This will enable the researcher to draw conclusions on the nature of messages sent across Facebook and Twitter as people interact with one another.

\section{RELATED STUDIES}

Habtoor and Almutlagah (2018) explored intra-sentential code-switching among bilingual Saudis on Twitter. The study made use of 12 bilingual Saudi females on Twitter who differed in age and education. Statistical and qualitative methods were used in analysing the data. The finding of the research revealed that code-switching occurs frequently among Saudi users of Twitter. At the level of particular syntactic categories in Arabic code-switching, nouns were the most often switched elements in the corpus. The research also discovered that most inserted words in English were related to the internet and other social aspects. This research and the present one are similar in the sense that both obtained data from Twitter and analysed them from a sociolinguistic perspective. The difference lies in the fact that the former examines code-switching but the latter studies the communicative action of interactions in Facebook and Twitter.

Ibe-Kalu (2016) examined the language use of social networking sites (SNS) among students of the University of Nigeria, Nsukka. The objectives of the study were to identify the various types of SNS and their features, how SNS enhances communication among students, and to determine the implication of the proficient use of the language of SNS on the students. The study made use of 244 respondents from four hostels in the University of Nigeria, Nsukka. The study made use of the respondents' individual posts on social media. The research discovered that the various types of SNS are Facebook, Blackberry Messenger, Twitter, Whatsapp, and Instagram, which have 150 million users each. The finding of the research also reveals that students of the University of Nigeria, Nsukka make use of smileys/emojis, abbreviations, acronyms and code-switching during their interaction on SNS. The research also discovered that the implication of the proficient use of the language of SNS on the students is that it enables them to create new words, which enrich the vocabulary of the English language. The research, from its findings, refutes the claim that the language 
of SNS influences students in their day-to-day offline interaction. The research concluded that SNS is a sociolect in the sense that it can be faulted outside the online community of social networking. This research and the present one are similar in that they examine language use in SNS. Their difference lies on the path of approach. The former analysed its data descriptively whereas the former analyses its data with the theory of communicative action. In addition, the former situates its research on the University of Nigeria, Nsukka (UNN) students alone, while the latter makes use of data from posts of UNN students and some selected political discourses from Twitter.

West (2015) researched on liking, commenting and non-response on Facebook from a sociolinguistic perspective. The purpose of the study was to analyse audience behaviour on Facebook. The researcher combined ethnographic methods of data collection with the objective of interactional sociolinguistics and conversation analysis to illuminate the influences on members' choices between such options. From the study, it was discovered that 'Like' on Facebook functions as a quick and inexplicit back-channeling device that fills the second pair slot that a post creates, avoiding the hearable silence that otherwise exists when a post receives no response from the newsfeed audience. In addition, the research revealed that audience members comment on posts based on the present contextual aspects that the poster has made available in their post linguistically and phonologically. The research concluded that Facebook is a site of great importance to computer-mediated communication researchers due to its longevity and continued prominence among SNSs. The research of West and the present one are similar in that they examine messages on SNS from a sociolinguistic perspective. The two researches are different from the standpoint of analysis. The former used ethnography and conversational analysis for data analysis whereas the latter adopts theory of communicative action.

Kim, Li, Weber and Oh (2014) in their research on a sociolinguistic analysis of Twitter in multilingual societies examined the interplay of language and network structure in diverse multilingual societies and quantifying the degree to which users are the 'bridge-builders' between monolingual language groups. The research collected Twitter data from Qatar and Switzerland, and Quebec province in Canada. The findings of the research revealed that monolingual users cluster together while bilinguals do not. More so, users speaking local language have more influence than others. In addition, the language-mixing ration of bilingual users closely mirrors the mix of followership. The research also discovered that bilinguals express informative/political/debatable topics in a local language, while posting event/tour/enjoyment topics in the English language. Whereas this research drew its data from European countries, the present research's data were drawn from posts made in Nigeria.

\section{METHODOLOGY}

This research adopts the descriptive survey research design. The Social Networking Sites (SNSs) used in this study are Facebook and Twitter because of their popularity and high number of users. A total of two hundred and seventy-five (275) messages sent in Nigeria were used for the study, which are comprised of five (5) posts from Facebok (three from MY UNN DREAMS group and two from IGBOIST group). One hundred and sixty-five (165) comments were selected from the Facebook posts. These posts bordered on educational and social aspects of life. On the other hand, three (3) tweets, which have political undertones, were obtained from Twitter. One hundred and two (102) comments were selected. These SNSs provided a platform from people to interact and seek answers to their questions or communicate their ideologies to friends and followers. As people interact on SNSs, they do so through the help of language. However, the data obtained from the selected SNSs will be approached from a communicative action perspective, which is an aspect of pragmatics. Insights from politeness and interpersonal pragmatics will also be employed for the analysis.

\section{NATURE OF ACTIONS IN FACEBOOK AND TWITTER INTERACTIONS}

Under communicative action, Habermas identified two kinds of actions: instrumental (self-gain) and strategic (for the good of all). One of the Facebook used is 'MY UNN DREAMS' University of Nigeria Nsukka (UNN) aspirants and UNN students assemble to discuss matters that concern. Sometimes, they may discuss matters that are not related to academics. This platform is where aspirants ask questions for clarification and students use this medium to get motivated and render pieces of advice to one another.

From the first post on, the poster made a claim, "UNN Students Are Naturally Proud..." This statement attracted several comments from members of the group. From the randomly selected comments selected for this study, nine (9) participants disagreed with the poster whereas sixteen (16) participants agreed. This ratio of agreement: disagreement (16:9) suggests that the poster was strategic in his action because the claims he made were not for his selfish gains but to motivate other students to continue to be proud as a UNN student. Another piece of evidence that supported the strategy of the poster is that out of the sixteen (16) persons that agreed with the post, four (4) persons defended their agreement by asserting: "Lions dont [sic] bow to chickens," "Have you seen a timid lion before? Bold is the word," "There are only two Universities in Nigeria. 1. UNN \& 2. OTHERS..." "the prestige." On the other hand, only one person defended his disagreement by asserting that there is nothing to be proud of in a University where thieves exist. From the foregoing, it can be adjudged that poster's post is strategic in its action. At the level of interpersonal pragmatics, it is seen that through the comments, participants construct their identity. The students that agreed to the post show how proud they are of being a student of the University of Nigeria, Nsukka. The people that disagreed did so because of their dissatisfaction of being a student of UNN. Notwithstanding the stance taken by the participants they 
ensured that they saved the face of other interactants but non-students of UNN may frown at being referred to as 'chickens' because it threatens their face wants.

However, in some of the comments, some participants digressed from the major topic of the post. This occurred because often times, comments are built upon the previous comment or commenter. As people commented on the post, a suave young lady commented, and the succeeding commenter deviated from the post and commented on the last commenter by saying, '(Name of the last commenter) u resemble 1 gal wey meet for Tokyo in last yr' (...You are a replica of a girl I met in Tokyo last year). This comment attracted further comments, which are instrumental in action because the intentions are self-gratifying. Some of the comments include: "Okay...I'll show you around...leave Ken...I'll settle him later." "I will guard u on anything including termpapers \& assignments." "but wait does it mean the freshers should now wait until everything is taken. Rara (never) I must catch them young." Evident in the above comments are instances of utterances that have rewards as their motivations. The participants offering help to the young girl in question were all boys and the motive for their eagerness to help can be seen in the statement, "I must catch them young." These comments above also point to the identity of the persons who commented them. They presented themselves as people that cherish rewards over good deeds. As a result, their actions are adjudged instrumental because they put their personal interest over general interest.

In the second post, the poster was relaying information on the state of affairs of UNN's supplementary list.

Excerpt 1

Poster: I have confirmed that the list have been screened by jamb since few days ago the latest news now is that the sch ict unit are almost done with the inserting of names on their portal. In this case the ict bosses will be contacting the registrar registrar to ask him for further names for aspirants with long legs and a big god in this case the sch registrar and the Vc are the ones delaying the list because I heard that few names were submitted in the registrar's office on monday since they are done with it will take the ict just few hours to convert it to pdf don't forget that UNN will be releasing 2/3 lists that same day...

Out of the selected sixteen (16) comments, six (6) participants agreed with the poster whereas nine (9) persons did not. From this, the action arising from the post is instrumental and not strategic. It appears that the poster wants to use the post to attract attention to himself. Those who agreed with him simply said 'Amen' to the declaration made by the poster that they (aspirants) will make it in the list. This response reveals that the identity of the responders as prospective students who are in dire need of admission into the university. Those who disagreed are possibly students of the University already and they defended their disagreement by saying, "Stop deceiving emotions," "So its no more dis week, its now next week abi". This set of commenters have heard and read series of fake news on the release of admission list. One of the commenters used the bald-on record politeness strategy when he said "Stop deceiving emotions".

Another participant (a new student) in "MY UNN DREAMS" group asked a question, "Pls as a fresher i need advice, btw hostel $\mathrm{n}$ offcampus which is advisable for a fresher." The poster was simply requesting advice from his senior colleagues to know if he will stay in the hostel or off-campus. The question is borne out of strategic action because the poster will not be the person to benefit from the responses; other freshmen in the platform will benefit from the constructive responses that will be given by students and alumni of the University. From the comments on the post, six (6) persons suggested that hostel is better for a fresher because of security, information dissemination, interaction, improved power and water supply. On the other hand, four persons suggested that off-campus is better because the hostel is dirty; one can still get information while in off-campus and because they saw no advantage in staying the hostel. From the data, those who defended that hostel is better for a fresher at least for the first year in the University argued strategically whereas those who defended the off-campus choice did not give any concrete reason why they suggested off-campus. This made their actions to be instrumental. More so, the comments of the participants show their ideological leaning on the hostel - off-campus issue. One thing that is worthy of note is that the stance each of the commenters took may be from personal experience or the review they have heard from people who have stayed both in the hostel and off-campus.

One of the participants in IGBOIST group (a group that brings together many Igbo people) asked a question: "Is it right for a single lady to hang out with a married man." The post attracted over two thousand seven hundred comments. From the randomly selected 22 comments, 13 participants said that it is a wrong thing with the reasons that karma is real, it is not in Igbo tradition, do to others what you would want them to do to you. The reasons given are strategic because the commenters gave reasons based on facts and culture. On the other hand, two persons said there is nothing wrong with it. This latter response is instrumental because the responders gave their responses without considering the effects of a cheating husband will have on the wife. According to Nwala (1994), Igbo morality is based on good and upright living which include fidelity in marriage and celibacy. In Igbo traditional setting, the virginity of a lady is valued in that when a man marries a lady and discovers that the lady is not a virgin, it is his right to send the lady back to her parents and demand for a refund of the dowry he paid. It is in this line of thought that those who said it was wrong hinged on. Those who supported it may have done so because of their belief in liberalism.

Excerpt 2

Poster: Nobody is as secretive as a Nigerian travelling abroad... why is it so? 
The poster in the above excerpt asked why many Nigerian keep their travelling abroad as a secret. 93\% of thirty selected comments attributed it the fear of 'village people'. According to them, out of jealousy one can kill another. $7 \%$ of the comments remarked that the fear of 'village people' is baseless. From instances of mysterious death of successful people, the claim that the 'village people' or witches are the reason why people do not disclose their success is strategic. The identity of the commenters can be seen in their comments. The ideology that villagers are diabolic can be from experience or hearsay. Oftentimes, there are reports that someone travelled abroad and died in his sleep and there also cases where people travelled and they became successful.

Excerpt 3

Tweeter: We welcome H.E, Atiku Abubakar to d 2019 campaign trail. Nigerians would now decide b/w a candidate with a history full of CREDIBILITY crises, damning reports on CORRUPTION, both home, abroad \& from his former boss \& another candidate with an unblemished record in public service.

From the Twitter data, the first post used for this research has a political foundation. One of the 'Buharists' welcomed Atiku Abubakar to the 2019 presidential race and tagged the incumbent President of Nigeria, Buhari as credible and Atiku Abubakar as corrupt. The post, as at the time of data collection (12:07PM, Wednesday, October 10, 2018), attracted one thousand five hundred and ninety-eight comments. From the randomly selected forty-one (41) comments, twenty-six (26) persons disagreed with the tweet whereas three (3) persons agreed. Other comments were not centered on the tweet per se. What transpired was the case of Atiku's supporters and Buhari's supporters. This implies that those who disagreed are in support of Atiku whereas those who agreed with the tweet are in support of Buhari. As a result of this margin between those who supported and those who disagreed, the tweeter's action is adjudged instrumental. The first person to comment supported that the tweet's action is instrumental when the person listed Buhari's few friends who have been indicted for fraud and no serious action has been taken in that regard. One of the supporters of the tweet never gave any concrete reason for supporting the credibility (Buhari) versus corruption (Atiku) demarcation unlike some of the comments that gave reasons why they did not concur with the tweet. In their taking of stance, tweeps who replied to the tweet polarised between 'us' and 'them'.

Excerpt 4

Tweeter: It has been brought to my understanding that Atiku cannot travel to some part of the world; well, I think I will prefer a President who will spend most of his time dealing with Nigerians in Nigeria, not a someone who already knows the route to all the countries like a Pilot.

Two days after Atiku Abubakar was declared the flag-bearer for the People's Democratic Party for the 2019 Presidential race, former Head of State, Ibrahim Babangida through his Twitter handle reacted to the trending news about Atiku's ban from entering the United State of America on the grounds of corruption. He remarked that for him, he prefers a President who will spend most of his time dealing with Nigerians in Nigeria, and not someone "who already knows the route to all the countries like a Pilot." The tweet attracted many comments, which manifest in bipolar between 'ATIKUlated' supporters and Buharists. Everyone is trying to support the camp he/she belongs. One of the persons that tweeted his comment took a middle of the road approach says that "The two of them should come out for debate - no surrogate this time!" Following the comments made in reaction to the tweet, it can then be said that the Babangida's tweet has strategic action because it addresses the present situation of Nigeria. In a musical video shot by a Nigerian artiste known as Falz titled 'This is Nigeria', he referred to Buhari's first tenure as "four-year tenure, threeyear holidays". This is consonance with Babangida's position above. The strategic nature of Babaginde's tweet rests on the reason he gave for his position as regards who he was supporting during the 2019 presidential elections.

Excerpt 5

Tweeter: When Nnaji resigned as minister, GEJ [Goodluck Ebele Jonathan] replaced him with Nebo. When Stella was sacked, GEJ replaced her with Osita Chidoka from her state. But Seyelfa of Bayelsa was replaced with Bichi from Kano while Kemi from Ogun is replaced with Zainab from Kaduna.

Lastly, the tweet made by Reno Omokri, a member of PDP on the replacement of Ministers attracted a lot of comments from tweeps. The tweeter tried defending his former boss by saying that Goodluck Jonathan replaces Ministers with people from the same state whereas Buhari has 'northernised' Nigeria. The tweet was between strategic and instrumental. One of those that tweeted their comments remarked that even as federal character must be observed, competence should be the keyword in appointing a Minister. The stance taking in this tweet shows where the tweeter's loyalty lies. As a political discourse, the tweeter polarises between the People's Democratic Party's government and All Progressive Congress' government. For the tweeter, the former abides by the federal character whereas the latter flouts federal character. Because of the political affiliation of the tweeter, ascertaining the action performed by him becomes blurry.

\section{The World(s) Portrayed by InTERlocutors on FACEBOOK AND TwitTER}

Habermas' theory of communicative action identified a three-world concept of objective, social and subjective worlds. Individuals operating in the objective world argues based on truth and facts. Social world comprises the norms that govern a group of people and individuals operating in subjective world create alternative facts that are based on personal feelings and emotions. The first post from Facebook opened an avenue for participants to reveal the world they operate in. The poster itself, through the post, indicated that he belongs to the objective world notwithstanding that he 
did not give reasons for his assertions. On the other hand, the second post, the poster sought clarification, which was borne out of strategic action and expecting objective answers that will abide by the validity claims. The comments to the post are objective because the commenters outlined key issues that are factual and not based on feelings.

The fourth post from Facebook shows that the poster is operating in the subjective world. The social world frowns at adultery and unfaithfulness between a husband and a wife. Those who said that it is right for a single lady to hang out with a married man argued based on personal feelings and alternative facts instead of truth and facts. Those who said that it is wrong demonstrated that they operate in the objective world because: "It is not Igboic. It is not cultural. It is not civil. It is sinful. It is sacrilege in Igbo land".

From the data obtained from Twitter, the tweeter of the first tweet operates in subjective world because the assertion that Buhari has an "unblemished record in public service" is not factual. In line with the truthfulness validity claim of communicative action, the statement is untruthful. The second and third Twitter data bemoans the performance of Buhari's government and aim at persuading their followers to share the same ideology with them. Due to the fact that the tweeters backed up their claims with the facts, the tweeters operate in objective world.

\section{CONCLUSIONS}

This paper has examined the nature of actions and the three-world concept in the interactions of some selected Facebook and Twitter users. These actions and the three-world concept of Habermas' theory of communicative action emanate as people interact with one another to discuss things that concern them. One striking thing derived therefrom is that users who undertake strategic action back up their stance with factual reasons whereas most of the people who undertake instrumental actions do not give any reason for their claims. On the other hand, the study also revealed that most people operate in the objective world than in the subjective world.

Facebook and Twitter as well as other Social Networking Sites serve as platforms for people to reveal their ideologies. SNSs have proven to be good platforms for generating data for sociolinguistic analysis. The time has come in the academia when researchers will no longer be depend on questionnaires because the answers to research questions can be elicited from SNSs users. The study recommends that further researches from other aspects of sociolinguistics and pragmatics be conducted in order to tap into the benefits SNSs have for sociolinguistics in particular and linguistics in general.

\section{ACKNOWLEDGEMENTS}

The authors wish to thank Prof. C. U. Agbedo of the Department of Linguistics, Igbo and Other Nigerian Languages, University of Nigeria, Nsukka for suggesting this research. The authors thank the ' 017 MA class of the Department of Linguistics, University of Nigeria for their inputs when this paper was presented before them in October 2018.

\section{REFERENCES}

[1] Agbedo, C. U. (2015). General linguistics: Historical and comparative perspectives. Nsukka: KUMCEE Ltd.

[2] Alaslaa, S. A. (2018). A sociolinguistic study of code choice among Saudis on Twitter. A PhD dissertation, University of Michigan.

[3] Alvidrez, S. \& Rodriguez, O. F. (2016). Powerful communication style on Twitter: Effects on credibility and civic participation. Media Education Research Journal, 24(47), 89-97.

[4] Bailey, G. (2018). When social media meets sociolinguistics: Using Twitter to study language variation and change. Retrieved from https://personalpages.manchester.ac.uk/staff/george.bailey/twitter_workshop/twitter_slides.pdf on 03/10/2018.

[5] Boyd, D. \& Ellison, N. (2007). Social network sites: Definition, history, and scholarship. Journal of Computer-Mediated Communication, 13(1). https://doi.org/10.1111/j.1083-6101.2007.00393.x.

[6] Cecez-Kecmanovic, D. \& Janson, M. (1999). Communicative action theory: An approach to understanding the application of information systems. Proc. 10th Australasian Conference on Information Systems. Retrieved from https//pdfs.semanticscholar.org/29d6/ on 20/4/2018.

[7] Crystal, D. (2006). Language and the internet (2nd ed.). Cambridge: Cambridge University Press.

[8] Habermas, J. (1984). The theory of communicative action - reason and the rationalisation of society (Vol I). Boston: Beacon Press.

[9] Habermas, J. (1987). The theory of communicative action - the critique of functionalist reason (Vol II). Boston: Beacon Press.

[10] Habtoor, H. A. \& Almutlagah, G. F. (2018). Intra-sentential code-switching among bilingual Saudis on Twitter. International Journal of Linguistics, 10(2), 1-18.

[11] Ibe-Kalu, M. N. (2016). Language use of social networking sites among students of University of Nigeria, Nsukka. B.A. project, Department of Linguistics, Igbo and other Nigerian Languages, University of Nigeria, Nsukka.

[12] Kim, S., Wei, L., Weber, I. \& Oh, A. (2014). Sociolinguistic Analysis of Twitter in Multilingual Societies. Retrieved from https://www.researchgate.net/publication/266661025 on 4/10/2018.

[13] Lakoff, R. (1979). Stylistic strategies within a grammar style. Academy of Science Annals, 327, 51-78.

[14] Marwick, A. \& Boyd, D. (2014). Networked privacy: How teenagers negotiate context in social media. New Media \& Society, 1-17. doi:10.1177/1461444814543995.

[15] Nwala, T. U. (1985). Igbo philosophy. Lagos: Lantern Books. 
[16] Varis, P. \& Blommaert, J. (Eds.). (2015). Conviviality and collectives on social media: Virality, memes and new social structures. Journal of Language and Politics. https://www.tilburguniversity.edu/upload/83490ca9659d49a097dbff1f8978062b_TPCS_108_Varis-Blommaert.pdf on 03/10/2018.

[17] Wardhaugh, R. (2010). An introduction to sociolinguistics (6th ed.). Oxford: Blackwell Publishers.

[18] West, L. A. (2015). Responding (or not) on Facebook: A sociolinguistic study of liking, commenting, and other reactions to posts. A PhD dissertation, Faculty of the Graduate School of Arts and Sciences, Georgetown University.

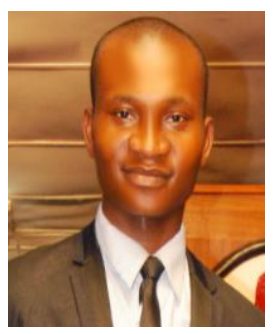

Sopuruchi C. Aboh was born in Aba, Abia State on 20th November. He had his Bachelor of Arts Degree and Master of Arts Degree in Linguistics at the University of Nigeria, Nsukka. Sopuruchi specialises in sociolinguistics and pragmatics.

He has published some articles including: "The ideology of post-truth in Nigerian cities: A discourse historical analysis", Journal of Linguistic Association of Nigeria, 22(1), 64-78 and "A comparative analysis of lexical prepositions in the Ibibio and Igbo languages", Macrolinguistics, 6(9), 36-45.

Mr. Aboh is a member of Pragmatics Association of Nigeria, Nigeria Ecolinguistics Association, and Nigerian Institute of Translators and Interpreters.

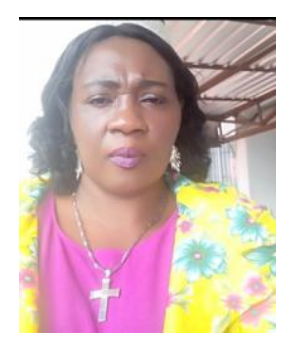

Obiageli C. Ezeudo was born in Onitsha, Anambra State on 1st August. She has Bachelor of Arts Degree, Master of Arts Degree and PhD in Linguistics at the University of Nigeria, Nsukka. Obiageli specialises in Psycholinguistics and Applied Linguistics.

She has published "Sound symbolism in Igbo: A Magnus approach", Journal of Linguistic Association of Nigeria, 20(2), 104-108.

Dr. Ezeudo is a member of Pragmatics Association of Nigeria, and Linguistic Association of Nigeria. 